\title{
INCREASING ORGANIZATIONAL PERFORMANCE AND COMPETITIVE ADVANTAGE: A TEAM PERSPECTIVE IN STRATEGIC HUMAN RESOURCES MANAGEMENT
}

\author{
DOI: 10.17261/Pressacademia.2017.710 \\ RJBM-V.4-ISS.3-2017(9)-p.326-335
}

\section{Meral Dulger ${ }^{1}$}

${ }^{1}$ Marmara University, Department of Business Administration, Bahçelievler Campus, İstanbul, Turkey. meral.dulger@marmara.edu.tr

\section{To cite this document}

Dulger, M., (2017). Increasing organizational performance and competitive advantage: a team perspective in strategic human resources management. Research Journal of Business and Management (RJBM), V.4, Iss.3, p. 326-335.

Permemant link to this document: http://doi.org/10.17261/Pressacademia.2017.710

Copyright: Published by PressAcademia and limited licenced re-use rights only.

\begin{abstract}
Purpose - Job designs based on individual employees may pose challenges such as delays, failure to fulfill obligations and/or misunderstandings that may reflect negatively on performance and ultimately competitive advantage. Alternatively, this paper proposes teams to efficiently utilize human resources.

Methodology - Propositions that can be used as potential research questions are derived through reviewing the relevant literature. Findings- Instances where individual employees fall short of considering each and every aspect of a given job are becoming ever so common. Teams, however, are mechanisms through which different individuals with different specialties and can come together and this synergy is coordinated towards a common goal. Accordingly, teams seem to have potential in efficient use of human resources.

Conclusion- Teams provide an organization and coordination tool for human resources practices. It is believed that teams have considerable potential in terms of increasing organizational performance and competitive advantage. Hence, teams are suggested as mechanisms upon which modern job designs should stand on.
\end{abstract}

Keywords: Team, strategic management, competitive advantage, strategic human resources management, job design JEL Codes: M12, M54, 015

\section{INTRODUCTION}

Organizations in this age are constantly on the lookout for ways to efficiently utilize their human resources in order to address the needs stemming from the constantly changing and complex marketplace. The foremost reason for this quest is, as Wright et al. (1994) puts it, the fact that efficient human resources management is one of the best ways to sustain competitive advantage. Thanks to global and technological advances, the jobs within organizations have rapidly become intangible and complex. Now, work is more abstract than physical, more likely to be designed for teams than for individuals, and more likely to cross boundaries than to be confined within particular organizations, departments or functions (Mohrman et al., 1998:154).

Therefore, it is expected that teams form and spread, reinforcing the perception that intraorganizational boundaries can be easily crossed and in time, these formal distinctions will act even less as barriers to collaboration than as facilitators (Mohrman et al., 1998). Organizations more and more rely on teams to do much of the work conventionally carried out by individuals in response to increasing demands for effectiveness and flexibility posed by rapidly changing organizational environments in the face of current global and dynamic organizational environments (Griffith and Neale, 2001). To this end, by building effective teams, organizations benefit by improving their decision-making capacity, enhancing employee commitment and involvement, increasing organizational collaboration and cooperation, and providing performance growth and development opportunities for employees (Gilley and Gilley, 2007).

Furthermore, human resources are a crucial component in the strategic management process; especially in the strategy execution phase. It would be quite logical to posit that the quality of the expected strategic performance outcomes depends on the good management of human resources. This stream of thought is derived from Porter (1985), Barney (1991) and Grant's (1996) well-known studies where each calls for a link between internal resources with intended strategy and means for gaining competitive advantage. As human resources are a vital part of the resources that organizations 
depend on to perform well, the relationship between human resources management practices and organizational performance were verified in the studies of Huselid (1995), Boselie et al. (2005), Boswell (2006), Combs et al. (2006) and Guest (2011). Nevertheless, Buller et al. (2012) contend that merely designing human resources management practices and systems that are aligned with strategy is not sufficient by itself. They explain that there is a need to "align the intended strategy with execution by creating the necessary human capital (i.e., clear expectations, capabilities, and motivation of employees) along with the social capital (i.e., relationships, processes, and systems) to effectively implement strategy" (ibid.:46). In other words, the actual test is to bond competent and motivated people with complex and dynamic strategic objectives, organizational processes, and resulting work requirements (Ostroff and Bowen, 2000).

As teams are mechanisms through which different individuals with different specialties and can come together and this synergy is coordinated towards a common goal, they provide many advantages in terms of the aforementioned discussion. The remainder of this endeavor explains these positive outcomes from the standpoint of strategic human resources management in terms of deployment of teams. Ultimately, the main premise here is that teams provide organization and coordination tool for human resources practices. It is believed that teams have a considerable potential in terms of increasing organizational performance and competitive advantage. Also, another motivation behind this paper is to encourage human resources scholars to explore deeper into the team mechanisms and distinguish how they contribute to organizational performance and competitive advantage.

Keeping these issues in mind, the next section explains the effects of current business world on organizations and how teams might provide a potential solution in addressing the aforementioned competitive pressures.

\section{THE EFFECTS OF THE CURRENT MARKET MILIEU ON ORGANIZATIONS}

Today, the constantly changing political, economic and business environments push organizations to address these factors as rapidly as possible. The elements of organizations are inevitably interdependent and supportive of one another; however, their alignment when dealing with complexity and constant change is of utter importance. The performance pressures coming from the environment today have exceeded the capacity of the traditional, functional and hierarchical organizations to effectively coordinate and integrate (Galbraith et al., 1993; Galbratih, 1994). Traditional approaches which rely on hierarchically determined decisions, goals, rules, programs and job descriptions are insufficient in the dynamic, complex and demanding world now faced by many companies (Mohrman et al., 1995: 9). Therefore, in dynamic, complex and uncertain settings, organizations have to build on and subdivide their parts to be able to attend to all the relevant elements of the environment (Lawrence and Lorsch, 1969).

From the standpoint of human resources, it is has obviously become more challenging to recruit individuals who can perform well under the stated circumstances. Furthermore, the unique skills and expertise of employees fall short of considering each and every aspect of a given job. For instance, a particular employee while being very adept in technical skills might lack the competences or information to comprehend the reflection of her/his decisions on customer dynamics or vice versa. Accordingly, human resources departments inevitably increase the range of skills, expertise and experiences required from a single job applicant. As there is a natural limit to one individual's competences and expertise, this advance in the lists of criteria comes face to face with an impossible riddle to crack.

Still, there seems to be a way around these challenges. The advances in information technologies break down barriers in the sense that employees at the lowest levels of an organization now theoretically have access to information that would allow them to make informed decisions about matters that used to be dealt with higher levels in the organization (Mohrman et al., 1995). As it becomes easier for people in different work units to communicate, it also becomes easier for them to collaborate (Mohrman et al., 1998). Therefore, they conceive that teams form and spread, reinforcing the perception that intraorganizational boundaries can be easily crossed, and in time these formal distinctions will act even less as barriers to collaboration than as facilitators.

In addition, Griffith and Neale (2001) note that organizations more and more rely on teams to do much of the work conventionally carried out by individuals in response to increasing demands for effectiveness and flexibility posed by rapidly changing organizational environments. This is particularly true for settings where work is either highly-interdependent or rapidly changing, then, there comes about a strong argument for the basic organizing unit being a team rather than an individual (Galbraith et al., 1993). Hence, Hackman (2002) suggests that the use of teams has become an ever-increasing popular work design in all types of organizations. To this end, by building effective teams, organizations benefit by improving their decision-making capacity, enhancing employee commitment and involvement, increasing organizational collaboration and cooperation, and providing performance growth and development opportunities for employees (Gilley and Gilley, 2007). Seeing this line of thought, it can be said that teams can potentially contribute to organizational performance and competitive advantage. 


\section{THE PLACE OF TEAMS IN ORGANIZATIONS}

Teams are essentially established as forums in which various interdependent specialties can integrate their work to accomplish collective goals (Katzenbach and Smith, 1993; Mohrman et al., 1995). Team members are interdependent for accomplishing their goals and they affect the result through their interactions with one another. Hence, it could be said that team members have mutual commitment which engenders performance greater than the sum of the performance of its individual members or synergy.

As the complexity of the workplace continues to grow, organizations increasingly depend on teams (Salas et al., 2008). Some of the industries where teams are employed are aviation, the military, health care, financial sectors, nuclear power plants, engineering problem-solving projects, manufacturing and services. Examples of companies that employ teams include Miller Brewing Group, Pfizer, Colgate-Palmolive Company, Eastman Chemical Company (Wellins et al., 1994) along with the well-known examples of NASA, Google, Hewlett-Packard, Motorola, AT\&T, Xerox, Boeing, General Electric, Saturn and so forth.

The use of teams and teaming mechanisms to integrate organizations laterally has increased dramatically in recent years and many production settings have found that they could significantly improve their effectiveness by establishing teams that have responsibility for the "whole" of the work (Mohrman et al., 1995). Galbraith (1973: 53) points out that teams involve design decisions concerning the basis of the team, the composition of membership, the levels at which they are to operate, the range of their discretion and the frequency of their meetings. Teams are typically organized hierarchically and occasionally dispersed geographically; they must incorporate, synthesize, and share information; and they need to coordinate and collaborate as task demands alter during a performance period to realize their assignment (Salas et al., 2008).

Within the framework of this endeavor, teams are thought as platforms where individual limits can be elevated. The various members would be able to make up for each other's limitations. At the same time, it is supposed that the synergy stemming from their cumulative skills, expertise and experiences will result in increased efficiency and productivity levels. From this point of view, teams are proposed as mechanisms upon which modern and cross-functional job designs should stand on as they have the potential to address organization and coordination needs. By employing teams, organizations are thought to reinforce their organizational performance levels thereby increasing competitive advantage. The foundations of these propositions are explained in the following section that covers the pertinent literature.

\section{EVIDENCE FROM THE LITERATURE}

This section covers the relevant literature concerning to the discussion above. The purposes and advantages of teams are utilized as the building block of three propositions that follow. There is an uncharted research gap in the literature about how teams might act as the basis of job design and how such designs might affect organizational performance and competitive advantage. If this connection is theoretically developed further and explored via empirical studies, a considerable amount of contribution to the literature could be achieved. The propositions put forward below are thought to appropriately cover the issue at hand and can be used as potential research questions for those academics who are motivated to explore more about this topic.

\subsection{Purposes and Advantages Teams}

The literature provides ample information about the purposes and advantages of teams. The following points summarize the main points about this topic and they were mainly the spark behind this paper:

$>$ Integrating and coordinating various parts of a particular organization (Galbraith et al., 1993; Galbraith, 1994).

$>$ Accommodating complex processes better than hierarchical and functional approaches as teams prove themselves as mechanisms to address coordination needs in a timely and cost-effective manner (Mohrman et al., 1995).

$>$ Potentially producing products and delivering services faster than competition does at lower cost and higher quality (Mohrman et al, 1998: 165)

$>$ Boosting productivity, flattening of organizations, needing more flexibility and speed for decision making purposes, workforce diversity, quality, and customer satisfaction (Larson and LaFasto, 1989; Hollenbeck et al., 2007; Gibson et al., 2009)

$>$ Responding to a fast-changing environment, facilitating learning, conveying financial advantages, and assisting change better than can a set of individuals that does not share a common objective (West, 2004)

$>$ Being an integral part of business success, contributing to competitive advantage, a way of pooling ideas, expanding and improving work processes and job (re)design, enabling direct participation and empowerment leading to better decision-making and more creative solutions and fostering motivation while helping reduce conflicts and miscommunication (Kang et al., 2006: 1682). 
$>$ Using teams when an intricate problem requires employees with various aptitudes and functional proficiency to work together especially when making the wrong decision is too costly for a particular organization (Sassenberg et al., 2007).

$>$ Using teams when errors trigger severe consequences; when the task complexity surpasses the aptitude of an individual; when the task environment is ill-defined, ambiguous, and stressful; when numerous and rapid decisions are required; and when the lives of others rely on the joint insight of individual members (Salas et al., 2008).

As depicted by these points, teams seem to be more than capable as job design elements. Also, seeing these qualities, teams can be regarded as tools to support the realization of strategic goals. As the execution phase of organizational strategies is highly dependent on human resources and their management, teams appear as elements that can contribute positively to organizational performance and ultimately competitive advantage. Unfortunately, there is a gap in the academic literature in terms of theoretical and/or empirical studies exploring how team mechanisms as job design tools influence organizational performance and competitive advantage. The subsections below explain in what way these concepts might be related and derive relevant propositions that might pave the way for further academic research.

\subsection{Teams for Addressing Organization and Coordination Needs}

Under fierce, demanding and constantly altering market settings, the hierarchic structures seem to have a challenge in dynamically organizing and coordinating their activities. Keen (1997) contends that most organizational processes are crossfunctional and mostly cut across traditional functional boundaries. Thus, the ability to survive under the modern marketplace mainly rests on the capability to adapt to changes in market or customer requirements. Those who pass this test are by and large organizations that can organize and coordinate these cross-functional activities efficiently. In recent years, many companies have started to move away from a relatively functional and hierarchical structure to one with a focus on cross-functional teams and flattened organizational structures (Ostroff, 1999). Due to highly functionally oriented mindset, organizing and coordinating efforts of the managers may fall short of comprehending customer and/or market cases in a holistic manner. Further, such misunderstandings can cost organizations their reputations, market shares, stock prices, inefficient production activities and in worst cases, lost customers. Thus, teams can be said to provide linkages between a range of perspectives and functions within a given organizational setting. These linkages also aid the aforementioned coordination needs.

However, amplifying coordination mechanisms in an organization may lead to additional formal and/or informal management levels. When these are added to the previously existing management structure, the solution might become an even bigger problem. Wellins et al. (1991) and Marks et al. (2001) also sustain that teams are used in relieving coordination needs. Multiple participants can bring diverse points of view and proficiency that can be used to distribute information extensively within a given organization in order to make integrative decisions without propagating the management structure which is beyond hierarchy and bureaucracy (Mohrman et al, 1995). They also maintain that teams accommodate complex processes better than hierarchical and functional approaches as teams prove themselves as mechanisms to address coordination needs in a timely and cost-effective manner.

In addition, when different perspectives are linked, innovations are more prone to take place as this facilitates reframing of problems and solutions which would otherwise would have not been possible with individual perspectives (Senge, 1990). Furthermore, teams can be a way to handle lateral integration (Galbratih, 1973; 1994; Lawrence and Lorsch, 1969). They also underline that one of major design challenges is to integrate the work of various contributors and teams are structural mechanisms through which task interdependencies can be worked out, issues involving trade-offs between different perspectives can be resolved and solutions and approaches can be determined.

Furthermore, an organization can place individuals in those teams where their skills and knowledge can be used best, irrespective of what rank on a bureaucratic hierarchy they occupy (Mohrman et al., 1995). From a human resources stance, they also contend that the hierarchy is redefined in terms of the scope and domain of the decision making authority of a team within the system rather than in terms of a chain of individual reporting relations.

To put what has been discussed above into perspective, a comparison between traditional organizations and organizations that have team-based job designs is deemed to be vital. The following table exhibits how team-based organizations differ from traditional ones in terms of vision, structure and management style (adapted from Wellins et al., 1991). 
Table 1: Traditional versus Team-Based Organizations

\begin{tabular}{|l|l|}
\hline Traditional Organization & Team-Based Organization \\
\hline Management-driven & Customer-driven \\
\hline Work designed around functions & Work designed around processes \\
\hline No sense of ownership & Team owns a product, service, process \\
\hline Isolated specialists & Multi-skilled work force \\
\hline Many job descriptions & Few job descriptions \\
\hline Limited information & Shared information \\
\hline Many management levels & Few management levels \\
\hline Departmental focus & Whole business focus \\
\hline Management-controlled & Team-regulated \\
\hline Policy/Procedure-based & Values/Principles-based \\
\hline Selection-based employment & Training-based employment \\
\hline Top-down performance appraisal & 360-degree feedback \\
\hline Autocratic leadership & Participative leadership \\
\hline Change is temporary & Change is ongoing \\
\hline Seemingly organized & Seemingly chaotic \\
\hline Incremental improvement & Continuous improvement \\
\hline High management commitment & High worker commitment \\
\hline Soure:Adapted fom Welnset & \\
\hline
\end{tabular}

Source: Adapted from Wellins et al., 1991

Therefore, while providing room to deal with complexities of the business environment, teams also offer an organizational platform where individual employees find a platform to benefit from each other's resources (i.e. know-how, functional expertise, vision and so forth). As a particular employee cannot know every single thing to perform, it is inevitable for her/him to collaborate with others. The collaboration activities can be conducted within a team setting. As the literature exhibits, this is becoming a very common practice as competition increases and employing teams turns out to offer many advantages. When members of the team become interdependent, they are able to benefit from each other's resources while their combined efforts exceed their personal efforts. Thus, teams become a mechanism where individual resources can be distributed within a particular organization towards everyone's mutual benefit and at the end of the day; this will inject a sense of collective accomplishment. Therefore,

PROPOSITION 1: Teams are mechanisms through which organization and coordination needs of organizations are relieved.

\subsection{Teams in Job Design}

Having seen the advantages that teams can bring to organizations, Sundstrom (1999) describes teams as integral to organizational success in this global, fast-paced, customer-driven economy. Kang et al. (2006) inform that the call for teams and teamwork in organizations continues to be one of the more widespread and recurrent ideas of many practitioners and academics. Also, the use of teams in management often appears on the best practice lists such as that of Pfeffer's (1998). These facts clearly illustrate that teams should be a fundamental part of the post-modern organization as many organizations have started to rely on knowledge work more and more each day. Teams are more flexible than larger organizational groupings because they can be assembled more quickly and deployed, refocused and disbanded usually in ways that enhance rather than disrupt more permanent structures and processes (Katzenbach and Smith, 1993.: 15).

Also, it has been recognized that the fit between strategy and organizational design is a competitive advantage (Nadler et al., 1992; Galbraith et al., 1993). Thus, it is expected that teams fit with the changing nature of work and possess the elements that are required to address the issues arising from the changing requirements of the post-modern marketplace as well as better informed customers. Furthermore, this is a very valuable insight form the standpoint of job design as a function of strategic human resources. Work is now more abstract than physical, more likely to be designed for teams than 
for individuals and more likely to cross boundaries than to be confined within particular organizations, departments, functions and as a result, organizations have to become flexible, empowering and team-based (Mohrman et al., 1998: 154).

Under these changes, job designs based on individual employees may pose challenges such as delays, failure to fulfill obligations and/or misunderstandings in addressing environmental pressures. These challenges can stem from lack of information, subjectivity, limits on personal skills and competences. Now, the customers know a lot more than they did 50 years ago, they have many specific requirements and demands and since they have too many options in the market they are not loyal to brands. Also, these realities and their ramifications are far too intricate and complex for only the individual employee to understand and attend to. As hierarchies create a lot of over-head, repetition and waste just for the sake of running the business procedures, the hierarchical levels increase in numbers, the hopes of quickly addressing customer needs and market realities unfortunately decline. For example, approvals become problematic and time consuming as they need to travel higher up in the hierarchy or go to other departments. This leads to delays, conflict among employees and managers and eventually reflects on customers one way or another and at the expense of potential revenues of organizations. Based on the points indicated, it is presumed that designing jobs around teams might be a plausible option in the quest of making customers happy and having the ability to generate new ones.

From a micro point of view, conflicts among co-workers are more likely to occur in team environments because people from different functions, disciplines, departments and personal backgrounds view their worlds in dissimilar ways (Mohrman et al., 1998). This could be time consuming on the part of the organization. However, dealing with differences openly can help resolve conflicts and this will produce innovation and improve business performance (Mohrman et al., 1995). As teams provide a holistic view, the outcomes they produce are worth the time organizations invest.

From a macro perspective, there are many changes and the developments that happen almost simultaneously in the marketplace. In order to stay relevant, the organizations need to follow, analyze and make inferences on these changes and developments. This requirement inevitably drives organizations to look for ways to increase their information processing capacities. In accordance with the discussion above, one of the simplest ways to do so is through employing teams more frequently throughout organizations. Henceforth, it is supposed that teams provide a novel tool for increasing the learning and information processing capacity for organizations. Senge (1990) emphasizes the fact that teams can learn just like individuals do; however, a particular team's learning process is much more complex. This learning process is in line with the complexity of the global marketplace.

Wellins et al. (1994) note six recurring principles that guide the design from the hierarchical structure to one that accommodates teams at the end of their investigation of 20 firms that utilize teams. In the traditional structure, work is designed around functions, there is no sense of ownership, there are single skilled jobs, leaders govern teams, the support staff/skills are outside of the teams and managers make all organizational decisions. On the other hand, in the team design, work is designed around processes, teams own a product, service or process, there are multi-skilled and cross-trained individuals, teams govern teams, support staff/skills are incorporated into the teams and teams are involved in organizational decisions. An interpretation to these findings could be to say that the hierarchic structures that rely on individuals are task oriented, every member and function is independent from one another, inward-looking (i.e. knows what is going on only in one's own function/department/unit), logical (i.e. rational), divergent and have a fragmented approach towards matters. Alternatively, the structures that accommodate teams are process-oriented, contain many interdependencies in terms of relationships and functions they use, outward-looking (i.e. know what is going on with the whole process they work in and/or the whole organization), sensitive towards others, convergent in order to provide coordination and co-operation and have a holistic approach to matters. The following table summarizes the findings:

Table 2: Team versus Individual

\begin{tabular}{|l|l|}
\hline Team & Individual \\
\hline Process & Task \\
\hline Interdependent & Independent \\
\hline Outward & Inward \\
\hline Sensitive & Logical rationality \\
\hline Convergent & Divergent \\
\hline Holistic & Fragmented \\
\hline
\end{tabular}

Source: Adapted from Wellins et al., 1994 
Consequently, teams can be said to introduce hierarchies a new outlook and room for flexibility in the face of constantly changing dynamics of the business world. If not already, teams should be the building blocks of organizations rather than individuals (Leavitt, 1975; Nadler et al., 1992; Katzenbach and Smith, 1993; Mohrman et al, 1998). Hence, building on these premises, the following proposition is introduced:

PROPOSITION 2: Teams can be utilized as main building blocks of job design as they bring a well-rounded and crossfunctional approach towards addressing constantly changing complex market conditions.

\subsection{Teams for Increasing Performance and Competitive Advantage}

As previously noted, the importance of human resources in the strategic management process, particularly in the strategy execution stage, is undeniable. The quality of the expected strategic performance outcomes depends on the efficient management of human resources of a particular organization. Thus, it can be said that one of the leading factors to organizational performance are human resources practices. The relationship between human resources management practices and organizational performance were verified in numerous studies (i.e. Huselid, 1995; Boselie et al., 2005; Boswell, 2006; Combs et al., 2006 and Guest, 2011). Still, it is believed that a comparison between the performance levels of team-based organizations and traditional organizations from this perspective would be a considerable contribution to the strategic human resources management literature.

Besides, in the resource-based view of the firm, Barney (1991) identifies resources as the sources of competitive advantage and these resources need to be valuable, rare, inimitable and non-substitutable for sustained competitive advantage. Since human resources are an integral part of organizations' strategic assets, their value, rarity, inimitability and nonsubstitutability is in all reason of utter importance in strategic management processes. Especially, as the human resources of a company are the ones that literally execute an organization's strategy, their efficient management becomes quite important. Accordingly, the resource-based view may demonstrate the fact that strategies are not universally implementable, but are contingent on having the human resource base necessary to implement them (Grant, 1991). Further Wright et al. (1994) contend that while it is true that an individual or an elite group of individuals may create temporary competitive advantage, they argue that a more likely source of sustained competitive advantage is the larger pool of human capital that constitutes the entire organization. For them, the entire human resource capital pool may play a greater role in generating competitive advantage because they are directly involved in the production of the product or service (ibid., 18). Further, they propose that human resources practices aid in developing human resources as a source of sustained competitive advantage through creating and developing a high quality human capital pool (ibid., 24). Since teams are recommended as job design tools within the framework of this paper, team-based organizations might be performing better than their competitors and may have an edge over them. Unfortunately, the literature on this particular stance is very limited. In the same vein, it is put forward that the investigation of this specific topic would provide considerable input to the existing strategic human resources management literature. Putting the performance and competitive advantage factors together, the following proposition is maintained:

PROPOSITION 3: In organizations where teams are utilized, performance and ultimately competitive advantage could be affected positively.

\section{CONCLUSION}

In conclusion, teams prove themselves as a design element which provides organizations with flexibility, adaptiveness, responsiveness and customer-centricity. Teams can accommodate individuals from different functions and backgrounds that are seeking to achieve a collective goal that would otherwise hardly come together within the functional mindset of hierarchical structures. Thus, teams involve multiple participants with various perspectives and expertise which will in turn pave the way for well-informed and integrative decisions. Teams provide organizations with the cross-functional, wellinformed expertise, synergy, advanced flexibility and mobility they crave in this complex and uncertain business environment. As an organizational design component, teams seem to enable organizations to break their functional mindset and become more oriented towards their core processes that create value for their customers. Also, as another important implication, teams facilitate different members of the organizations with different agendas to come together on a common ground, which helps to balance out the interests between different processes and functions. These members find ways to set examples for each other and this creates a "checks and balances" system throughout the organizations which also encompasses the top management.

This undertaking underscores that by employing teams, even in relatively hierarchic structures, organizations can initiate cross-functional integration for mitigating the barriers between departments for greater efficiency and results. Once employees from different functions and backgrounds find a common ground where their total efforts exceed their individual efforts, their view of business is going to be expanded, employees and team members will come to understand what key processes involve more easily and see how they fit into the whole organizational structure. Leadership qualities of 
team managers may be supported for further self-development while the organizational culture change can be taken up to encompass and work with teams. Organizations can modify employees' individual attitudes towards teams and team membership by team motivation and team reward policies to improve organizational climate for the sake of easing crossteam activity inside or outside their companies.

Since the marketplace is steered by customers, the teams serve as flexible and adaptable mechanisms where they can be designed towards customer centricity when requirements change while supplementing and counterbalancing the weaknesses of the hierarchic structures. Thus, teams serve as an organizational mechanism that unites individuals in a participative and cooperative manner. When employees operate within a team, their interaction is likely to give rise to more ideas and innovations exponentially when compared to individual work. Teams create an environment that facilitates efficient organizational information creation and collection. Once information is turned into concrete organizational knowledge, basis for innovations that consumers crave are more prone to take shape. Thus, it is considered that teams are the perfect design component to introduce flexibility and perspective to otherwise rigid structures and bring organizations one step closer to being more organic, adaptable and innovative rather than being static in the face of complex change.

Teams offer a simple platform to accommodate individuals from different functions and backgrounds that are seeking to achieve a collective goal that would otherwise could hardly come together within the functional mindset of hierarchical structures. They also involve multiple participants with various perspectives and expertise which will in turn pave the way for well-informed, well-rounded and integrative decisions. Hence, teams can be said to have the potential to provide organizations with the advanced flexibility and mobility they probe in the contemporary complex and uncertain business environment. Seeing the compelling literature, this paper is an attempt to inspire the human resources literature to consider teams as a viable building block for job design.

Furthermore, the existing literature on teams and the relationship between human resources practices and performance along with competitive advantage seems promising for further inquiry. As the human resources pool is the one that executes strategy, the efficiency in managing this pool will most probably directly influence how each organizations perform and ultimately sustain competitive advantage. Teams as a building block for job design can be an option in efficiently managing human resources. Besides, teams can be treated as an organizational design element in elevating performance levels and sustaining competitive advantage. Still, there is a recognizable gap in the literature in terms of establishing this link. Hence, this paper is primarily developed to attract attention to this unexplored aspect in the strategic human resources management literature.

Last but not least, human resources practitioners can ultimately benefit from this proposed potential research. Seeing teams attracting academic attention, they will inevitably notice this cost-effective and efficient option in managing their respective human resource pools. The potential academic research can also encourage and motivate human resources practitioners to consider job designs based on teams more frequently.

Acknowledgement: This paper is built upon the literature review and interpretations of the author's Ph.D Dissertation "Significance of Team-Based Organizations in Business Process Orientation and Effectiveness: An Application to Service Firms in Turkey" (2011).

\section{REFERENCES}

Barney, J. (1991). Firm resources and sustained competitive advantage. Journal of Management, 17: 99-120.

Boselie, P., Dietz, G. and Boon, C. (2005). Commonalities and contradictions in HRM and performance. Human Resource Management Journal, 15(1): 67-94.

Boswell, W. R. (2006). Aligning employees with the organization's strategic objectives: Out of "line of sight", out of mind. International Journal of Human Resource Management, 17(9): 1489-1511.

Buller, P. F. and McEvoy, G. M. (2012). Strategy, human resource management and performance: Sharpening line of sight. Human resource management review, 22(1): 43-56.

Combs, J., Liu, Y., Hall, A., \& Ketchen, D. (2006). How much do high-performance work practices matter? A meta-analysis of their effects on organizational performance. Personnel Psychology, 59: 501-528.

Galbraith, J. R. (1973). Designing complex organizations. USA: Addison - Wesley Publication Company.

Galbraith, J. R. (1994). Competing with flexible lateral organizations. USA: Addison - Wesley Publication Company.

Galbraith, J. R., Lawler, E. E. and associates (1993). Organizing for the future: The new logic for managing complex organizations. San Francisco, LA: Jossey-Bass. 
Gibson, J. L., Ivancevich, J. M., Donnelly, J. H. and Konopaske, R. (2009). Organizations: Behavior, structure, process (13th ed.). New York, NY: McGraw-Hill.

Gilley, J. W. and Gilley, A. (2007). Manager as coach. Hartford, CT: Praefer.

Grant, R. (1991). The resource-based theory of competitive advantage: Implications for strategy formulation. California Management Review, Summer: 114-135.

Grant, R. (1996). Toward a knowledge-based theory of the firm. Strategic Management Journal, 17(Winter Special Issue): 109-122.

Griffith, T. L. and Neale M. A. (2001). Information processing in traditional, hybrid and virtual teams: from nascent knowledge to transactive memory. Research in Organizational Behavior, 23: 379-421.

Guest, D. E. (2011). Human resource management and performance: Still searching for some answers. Human Resource Management Journal, 21(1): 3-13.

Hackman, J. R. (2002). Leading teams: Setting the stage for great performances. Boston, MA: Harvard Business School Press.

Hollenbeck, J. R., Meyer, C. J. and Ilgen, D. R. (2007). Trait configuration in self managed teams: A conceptual examination of the use of seeding for maximizing and minimizing trait variance in teams. Journal of Applied Psychology, 5: 883-889.

Huselid, M. A. (1995). The impact of human resource management practices on turnover, productivity, and corporate financial performance. Academy of Management Journal, 38: 635-672

Kang, H.R., Yang, H. D. and Rowley, C. (2006). Factors in team effectiveness: Cognitive and demographic similarities of software development team members. Human Relations, 59, $1681-1710$

Katzenbach, J. R. and Smith, D. K. (1993). The wisdom of teams: Creating the high-performance organization. New York, USA: Harvard Business School Press.

Keen, P. (1997). The process edge: Creating value where it counts. Boston, MA: Harvard Business School Press.

Larson, C. E. and LaFasto, F. M. J. (1989). Teamwork: What must go right/what can go wrong. CA: Sage, Thousand Oaks.

Lawrence, P. R. and Lorsch, J. W. (1969). Developing organizations: Diagnosis and action. Reading, MA: Addison - Wesley Publishing Company.

Leavitt, H. J. (1975). Suppose we took groups seriously... In E. L. Cass and G. G. Zimmer (Eds.), Men and work in society; A report on the symposium held on the occasion of the 50th anniversary of the original Hawthorne studies. (pp. 67-77). New York, NY: Van Nostrand Reinhold.

Marks, M. A., Mathieu, J. E. and Zaccaro, S. J. (2001). A temporally based framework and taxonomy of team processes. Academy of Management Review, 26: 356-376.

Mohrman, S. A. and Cummings, T. G. (1989). Self-Designing organizations: Learning how to create high performance. USA: Addison Wesley Publishing.

Mohrman, S. A., Cohen, S. G. and Mohrman Jr., A. M. (1995). Designing team-based organizations: New forms for knowledge work. California, USA: Jossey-Bass Publishers.

Mohrman, S. A., Galbraith, J. R., Lawler III, E. E. and Associates (1998). Tomorrow's organization: Crafting winning capabilities in a dynamic world. California, USA: Jossey - Bass Publishers.

Nadler, D. A., Gerstein, M. S., Shaw, R. B. and Associates (1992). Organizational architecture: Designs for changing organizations.

Ostroff, F. (1999). The horizontal organization. New York: Oxford University Press.

Ostroff, C., and Bowen, D. E. (2000). Moving HR to a higher level: HR practices and organizational effectiveness. In Klein, K. J. and Kozlowski, S. W. J. (Eds.), Multilevel theory, research, and methods in organizations. (pp. 211-266). San Francisco: Jossey-Bass.

Pfeffer, J. (1998). The human equation: Building profits by putting people first. Cambridge, MA: Harvard Business School Press.

Porter, M. (1985). Competitive Advantage. New York: Free Press.

Salas, E., Cooke, N. J. and Rosen, M. A. (2008). On teams, teamwork, and team performance: Discoveries and developments. Human Factors, 50: 540-547.

Sassenberg, K., Jones, K. L., and Shah, J. Y. (2007). Why some groups just feel better: The regulatory fit of group power. Journal of Personality and Social Psychology, 2: 249-267.

Senge, P., (1990). The fifth discipline: The art and practice of the learning organization. New York, USA: Doubleday Currency.

Sundstrom, E. (1999). The challenges of supporting work team effectiveness. In Sundstrom, E. (Ed.), Supporting work team effectiveness (pp. 3-23). San Francisco: Jossey-Bass. 
Wellins, R.S., W.C. Byham, and J.M. Wilson (1991). Empowered teams: Creating self-directed work groups that improve quality, productivity, and participation. San Francisco, LA: Jossey-Bass Publications.

Wellins, R. S., Byham, W. C. and Dixon, G. R. (1994). Inside teams: How 20 world-class organizations are winning through teamwork. California, USA: Jossey - Bass Publications.

West, M. A. (2004). Effective teamwork: Practical lessons from organizational leadership (Second Edition). Malden, MA: BPS Blackwell.

Wright, P. M., McMahan, G. C., and McWilliams, A. (1994). Human resources and sustained competitive advantage: a resource-based perspective. International Journal of Human Resource Management, 5(2): 301-326. 